\title{
Autoradiographic evidence that transport of newly synthesized neuropeptides is directed to release sites in the X-organ - sinus gland of Cardisoma carnifex
}

\author{
E. Stuenkel ${ }^{1}$, E. Gillary ${ }^{2}$, and I. Cooke ${ }^{2}$ \\ ${ }^{1}$ Department of Physiology, University of Michigan, Ann Arbor, MI 48109, USA \\ ${ }^{2}$ Békésy Laboratory of Neurobiology and Department of Zoology, University of Hawaii, 1993 East-West Road, Honolulu, \\ HI 96822, USA
}

Accepted October 5, 1990

\begin{abstract}
Summary. Sections of isolated X-organ - sinus gland neurosecretory systems of the crab, Cardisoma carnifex, were studied by light- and electron microscopy with conventional and autoradiographic procedures. The somata only were exposed to a pulse of ${ }^{3} \mathrm{H}$-leucine $(5 \mathrm{~min}-5 \mathrm{~h})$ and the entire system perfused with chase medium for various times $(1-72 \mathrm{~h}$ ) before fixation. Within $1 \mathrm{~h}$, radiolabel is concentrated in Golgi complexes and nascent granules of both large and small somata. Label is undetectable in the terminal region following a $10 \mathrm{~h}$ chase. It is found in the nerve tract near terminals at $14 \mathrm{~h}$, while after a $19 \mathrm{~h}$ chase, label is concentrated in terminal profiles abutting blood sinuses of the neurohemal organ (sinus gland). Following a $72 \mathrm{~h}$ chase, label is distributed throughout the terminal region. Each of the six morphologically distinguishable terminal types shows labelling. These observations show that the vast majority of newly formed granules are initially transported to release sites of the perisinus terminals. They thus provide an explanation for previous analyses indicating that newly synthesized peptides are preferentially secreted.
\end{abstract}

Key words: Neurosecretion - Crustacea - Axonal transport - Neurohemal organ - Peptidergic neurons - Cardisoma carnifex (Crustacea)

Knowledge of the rate and route by which neuropeptidecontaining secretory granules reach sites of release or storage has recently taken on new importance. The "message" resulting from secretion by a peptidergic neuron has been shown in several systems to be conveyed by a mixture of peptides representing the posttranslationally processed fragments of a preprohormone, each of which may have a distinct target and a different effect (reviews: Newcomb et al. 1988; Sossin

Offprint requests to: $\mathrm{I}$. Cooke et al. 1989). Because processing proceeds within granules at rates that may be similar to or longer than the lifetime of the granules, it rarely goes to completion. Thus granules contain a complex mixture of the prohormone and its partially proteolyzed and modified derivatives that varies with the age of the granules. It has been shown that the peptide mixture in nerve terminals indeed varies with secretory demand (Newcomb and Nordmann 1987).

While the generality of the slow, often incomplete post-translational processing of peptides has been quite broadly established (Sossin et al. 1989), there is very limited information on rates and routes of granule movement through the often complex anatomical structures of neurohemal organs, nor has the question of non-terminal sites of secretion been closely examined in preparations other than the neurohypophysis. In the neurohypophysis, newly-synthesized neuropeptides are preferentially released (Sachs and Haller 1968). An explanation that has been often evoked is that newly-synthesized material is first transported to sites of release, identified as endings of axons against blood capillaries ("endings"), as suggested by autoradiographic studies (Kent and Williams 1974; Heap et al. 1975). The interpretation of these observations has recently been under reevaluation (Chapman et al. 1982; Nordmann 1985). Observations from two groups suggest that release occurs from preterminal axons and swellings, as well as endings in the neurohypophysis (Morris et al. 1988; Nordmann and Dayanithi 1988). Further, biochemical differences between old and new granules have been demonstrated in the neurohypophysis (Nordmann and Cazalis 1986) that could provide an alternative to spatial arguments in explaining selective release of the contents of newer granules.

In this study we present autoradiographic observations on peptide-secretory granule formation and transport in a crustacean neurosecretory system that can be isolated, intact, from the eyestalk of crabs, the X-organ 
- sinus gland (XOSG). Extensive studies of the XOSG (Cooke and Sullivan 1982) have shown that it shares the essential anatomical, physiological and biosynthetic features of other peptidergic secretory systems, including those of vertebrates (Stuenkel and Cooke 1988; Newcomb et al. 1988) and is therefore a relevant general model for study. Biosynthetic and biochemical studies have shown that at least $90 \%$ of the peptide content of the neurohemal organ (sinus gland) is derived by processing from a single precursor (Stuenkel 1983, 1986; Newcomb 1987) or a closely related family of precursors (Wiedemann et al. 1989). Furthermore a comparison of the relative abundance of biosynthetically radiolabelled, processed peptides released by a secretory stimulus with the mixture stored in the sinus gland is consistent with the preferential release of newly-synthesized peptides (Stuenkel 1983; Newcomb et al. 1985).

We have examined the route taken by peptide-containing granules by use of the isolated, intact neurosecretory system mounted in a chamber that holds the somata ("X-organ") and the axon terminals that form a compact neurohemal organ (the "sinus gland") in separate compartments with the axon tract passing through a sealed barrier between them. Thus exposure of the preparation to a radiolabelled amino acid precursor $\left({ }^{3} \mathrm{H}-\right.$ leucine) can be restricted to the somata, ensuring that radiolabel appearing in the axon terminals has been transported there. Analysis by light- and electron microscopic autoradiography of XOSG systems following various regimes of pulse-chase radiolabelling provides clear evidence for the mechanism underlying the preferential release of newly synthesized peptides in this preparation: transport of radiolabelled material is directed to terminals abutting hemolymph spaces, the apparent release sites; days later the radiolabelled material is found evenly distributed throughout the neurohemal organ.

\section{Materials and methods}

Preparation and radiolabelling. The experiments were performed on isolated, complete X-organ - sinus gland neurosecretory systems dissected from the eyestalks of the tropical semi-terrestrial crab, Cardisoma carnifex. The preparation, radiolabelling procedures and the pulse/chase chambers were the same as described previously (Stuenkel 1983, 1985, 1986). Briefly, the preparations were pinned with cactus spines in chambers formed in Sylgard divided by glass coverslips to leave a gap of about $0.5 \mathrm{~mm}$ through which the nerve tract passed. The gap was sealed with a Vaseline-paraffin mixture so that no fluid passed between the compartments. The viability of the preparations, as well as the adequacy of the seal, was checked by monitoring spontaneous impulses of the nerve tract across the recording resistance formed by the seal.

For all radiolabelling, except for pulses of 5 min or less, only the somata were exposed to the radiolabel. The region of axon terminals was superfused continuously during both the pulse and chase periods with nutrient-supplemented medium containing unlabelled leucine to avoid uptake of radiolabel which might have leaked into the terminal chamber and to reduce non-specific background binding. The cell somata were likewise superfused with nutrient-supplemented medium during the chase period.

The physiological saline consisted of $(\mathrm{mM}): 440 \mathrm{NaCl} ; 11.3$ $\mathrm{KCl} ; 13.3 \mathrm{CaCl}_{2} ; 26.3 \mathrm{MgCl}_{2} ; 23 \mathrm{Na}_{2} \mathrm{SO}_{4} ; 4$ HEPES, adjusted to $\mathrm{pH}$ 7.2. Pulse medium additionally contained $4 \mathrm{mg} / \mathrm{ml} \mathrm{D}$-glucose and $20 \mu \mathrm{M}{ }^{3} \mathrm{H}$-leucine $(120-160 \mathrm{Ci} / \mathrm{mM})$, except that in the $5 \mathrm{~min}$ pulse experiments the label was reduced by 10 - or 100 -fold. Chase medium consisted of physiological saline with the addition of $2 \mathrm{mg} /$ $\mathrm{ml} \mathrm{D}$-glucose and 10\% (in physiological saline) Medium 199 (Gibco). For chase periods longer than $3 \mathrm{~h}$, both penicillin $(100 \mathrm{U} / \mathrm{ml})$ and streptomycin $(100 \mu \mathrm{g} / \mathrm{ml})$ were added to the chase medium.

Fixation and autoradiography. At the end of the desired pulse/chase regime, the viability of the preparation was checked by recording spontaneous activity in the nerve tract as it passed through the chamber division. The preparations were then removed and pinned to a sliver of Sylgard and fixed for $3 \mathrm{~h}$ in a solution of $4 \%$ glutaraldehyde, $0.1 \mathrm{M}$ phosphate buffer and $0.35 \mathrm{M}$ sucrose. They were then washed in $0.1 \mathrm{M}$ phosphate buffer containing $0.45 \mathrm{M}$ sucrose; post-fixed in $1 \%$ osmium tetroxide in $0.1 \mathrm{M}$ phosphate buffer; dehydrated by passing through a series of concentrations of ethanol and then propylene oxide; then embedded in Ladd LX112 resin.

For light-microscopic autoradiography, thick sections $(1.5 \mu \mathrm{m})$ were mounted on cleaned glass slides. Slides were dipped in a $50 \%$ solution of Ilford L-4 emulsion and exposed for 7 days at $4^{\circ} \mathrm{C}$. The slides were developed in Kodak D-19 developer for $8 \mathrm{~min}$, rinsed in distilled water, fixed in Kodak Rapid Fixer for $8 \mathrm{~min}$ and washed in 5 changes of distilled water over a period of $5 \mathrm{~min}$. Thick sections were stained with Azure II - Methylene Blue for $30-60 \mathrm{sec}$.

For electronmicroscopic autoradiography, thin sections $(0.7$ $0.8 \mu \mathrm{m}$ ) were cut, picked up with a platinum loop, floated onto drops of distilled water on coated glass slides $(0.8 \%$ collodion) and dried down. Slides were dipped in $20 \%$ Ilford L-4 emulsion, and exposed in a light-tight box at $4^{\circ} \mathrm{C}$ for 14 days. Slides were developed in Kodak D-19 developer for 2 min, rinsed in distilled water $(30 \mathrm{sec})$, fixed in Kodak Rapid Fixer for $4 \mathrm{~min}$ and washed in 2 changes of distilled water over a period of 3 min. Collodion membranes with the exposed sections on them were floated off the slides into distilled water and 200-mesh nickel grids were placed over the sections. After the grids had dried (at least $1 \mathrm{~h}$ ), the sections were stained in $8 \%$ aqueous uranyl acetate for $15 \mathrm{~min}$ and post-stained in Reynold's lead citrate for $10 \mathrm{~min}$. Sections were examined and photographed by use of a Philips 300 electron microscope. A total of 18 radiolabelled preparations were examined by autoradiography for this study.

\section{Results}

Anatomy of the X-organ - sinus gland system favoring autoradiographic studies. The ability to isolate the entire neurosecretory system by dissection, the discreteness of

Fig. 1A-E. Light micrographs showing anatomy of X-organ - sinus gland neurosecretory system of crab (Cardisoma carnifex) eyestalk. A Photomontage of section through a system isolated by dissection as for all experiments. Note somata ( $X$-organ $)$, portion of sinus gland nerve tract ( $n t)$, and heavily staining terminal dilatations surrounding a complex of hemolymph sinuses (s) that constitute the neurohemal organ (Sinus Gland). B Section of sinus gland showing small size-class of terminal dilatations surrounding sinus $(s)$ and larger profiles further from sinuses. Individual terminals show variation in staining with azure II-methylene blue stain (see Fig. 3 A). C Autoradiograph of section of sinus gland from a radiolabelled preparation $\left({ }^{3} \mathrm{H}\right.$-leucine, $5 \mathrm{~h}$ pulse to somata only/19 $\mathrm{h}$ chase). Note aggregation of exposed grains around sinuses (see Fig. 3C). C Section through X-organ showing large and small somata lacking dendritic processes. $\mathbf{E}$ Section through $\mathrm{X}$-organ of radiolabelled preparation ( $5 \mathrm{~min}$ pulse $/ 1 \mathrm{~h}$ chase). Note clumping of grains in cytoplasm (see Fig. $2 \mathrm{~A}, \mathrm{~B}$ ). Scale in $\mathbf{E}$ same as in $\mathbf{B}, \mathbf{C}$ and $\mathbf{D}$ 


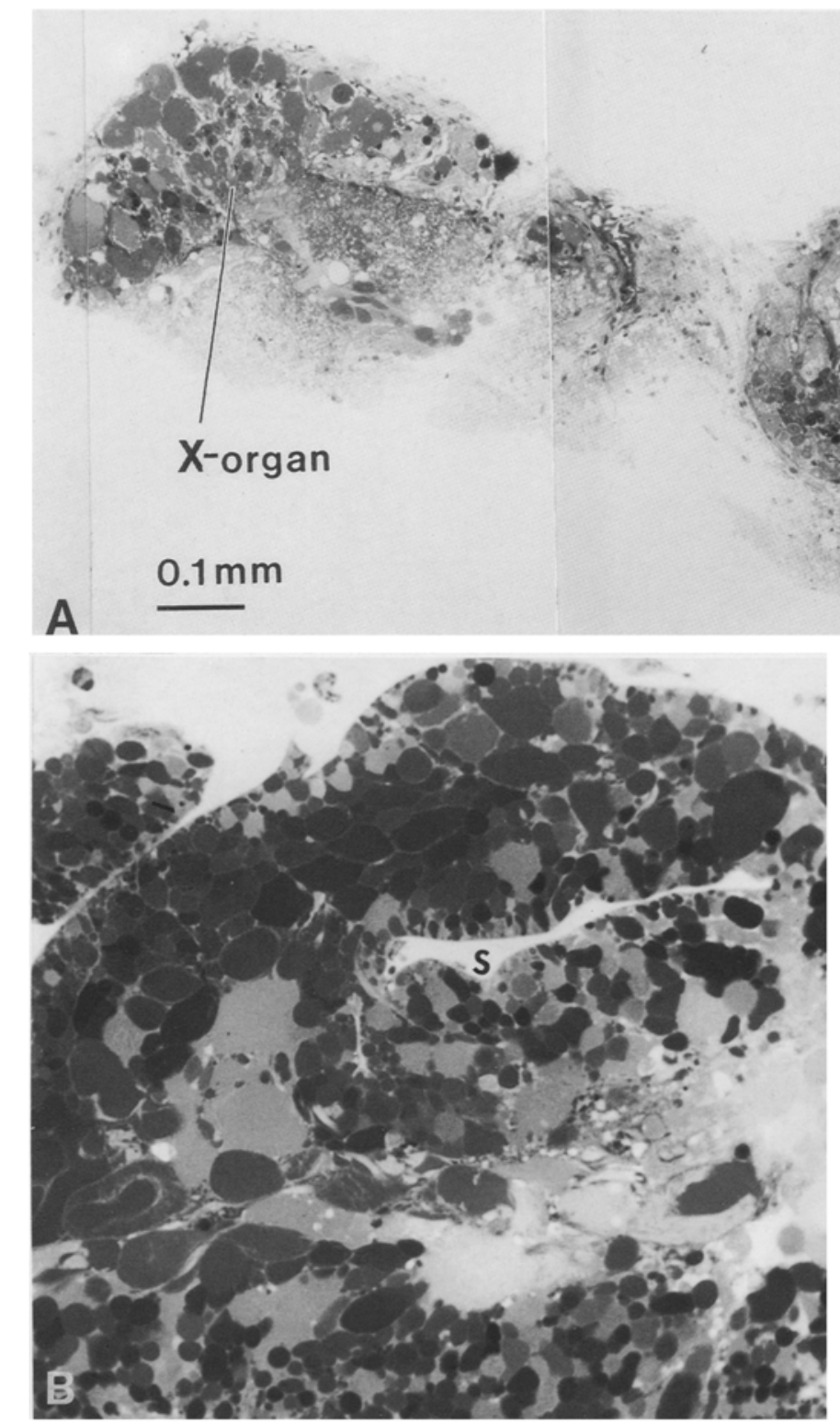

Sinus Gland

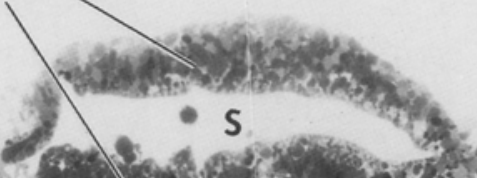

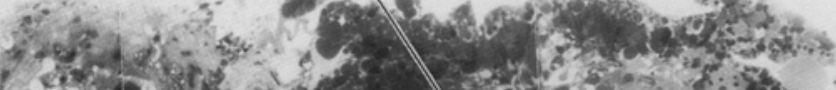

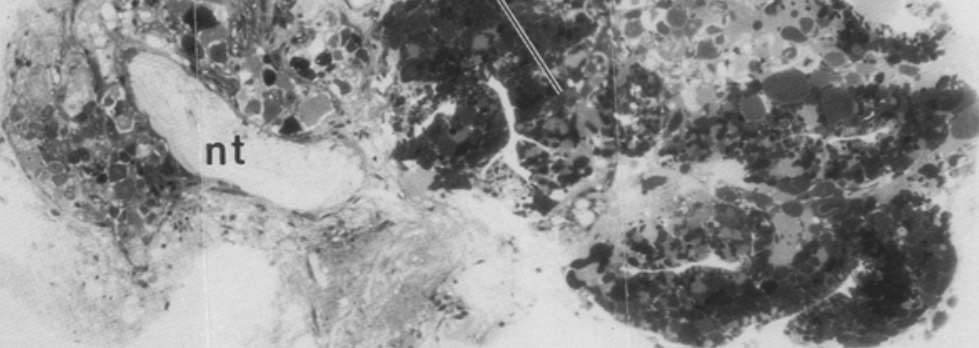

A
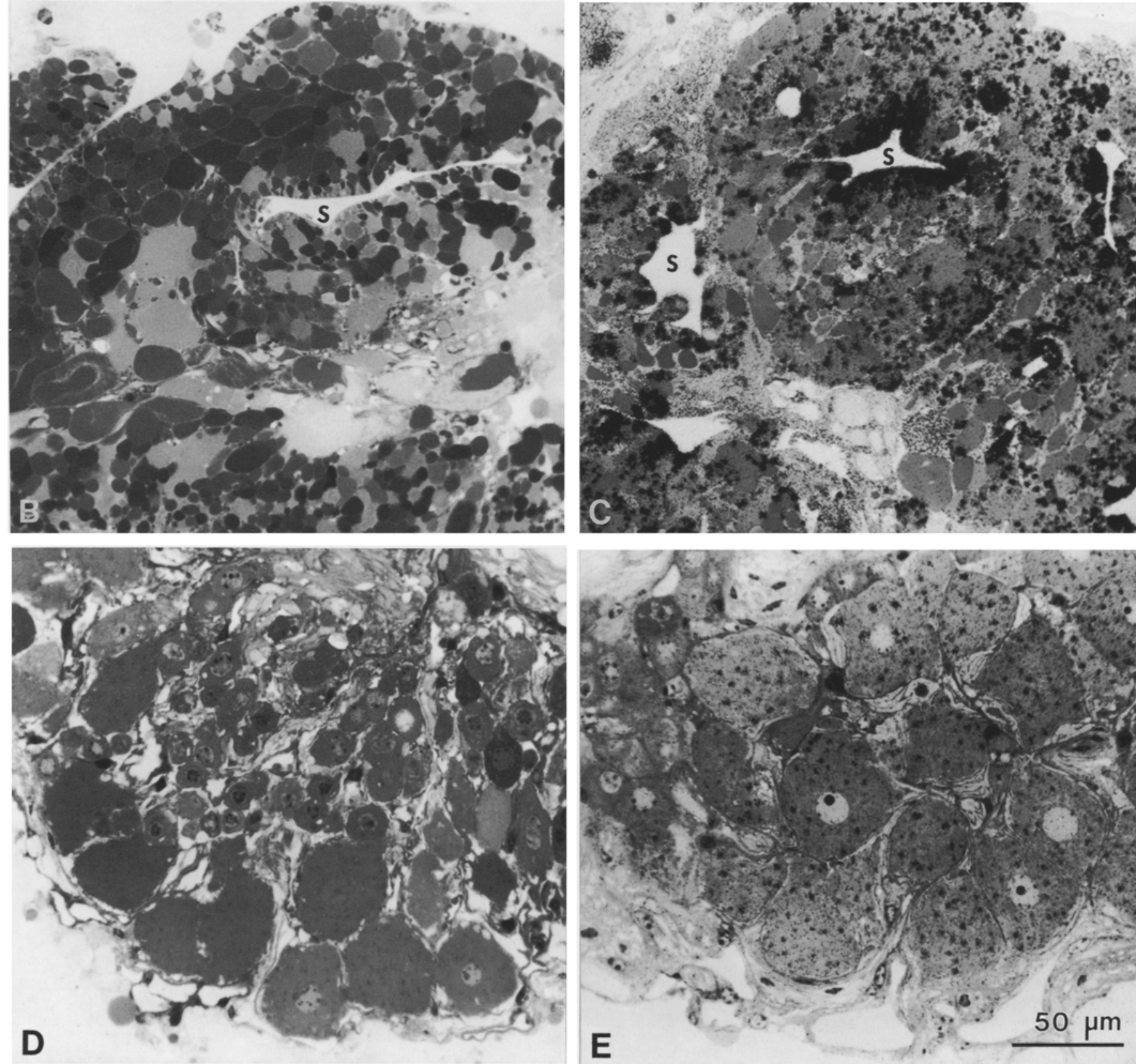

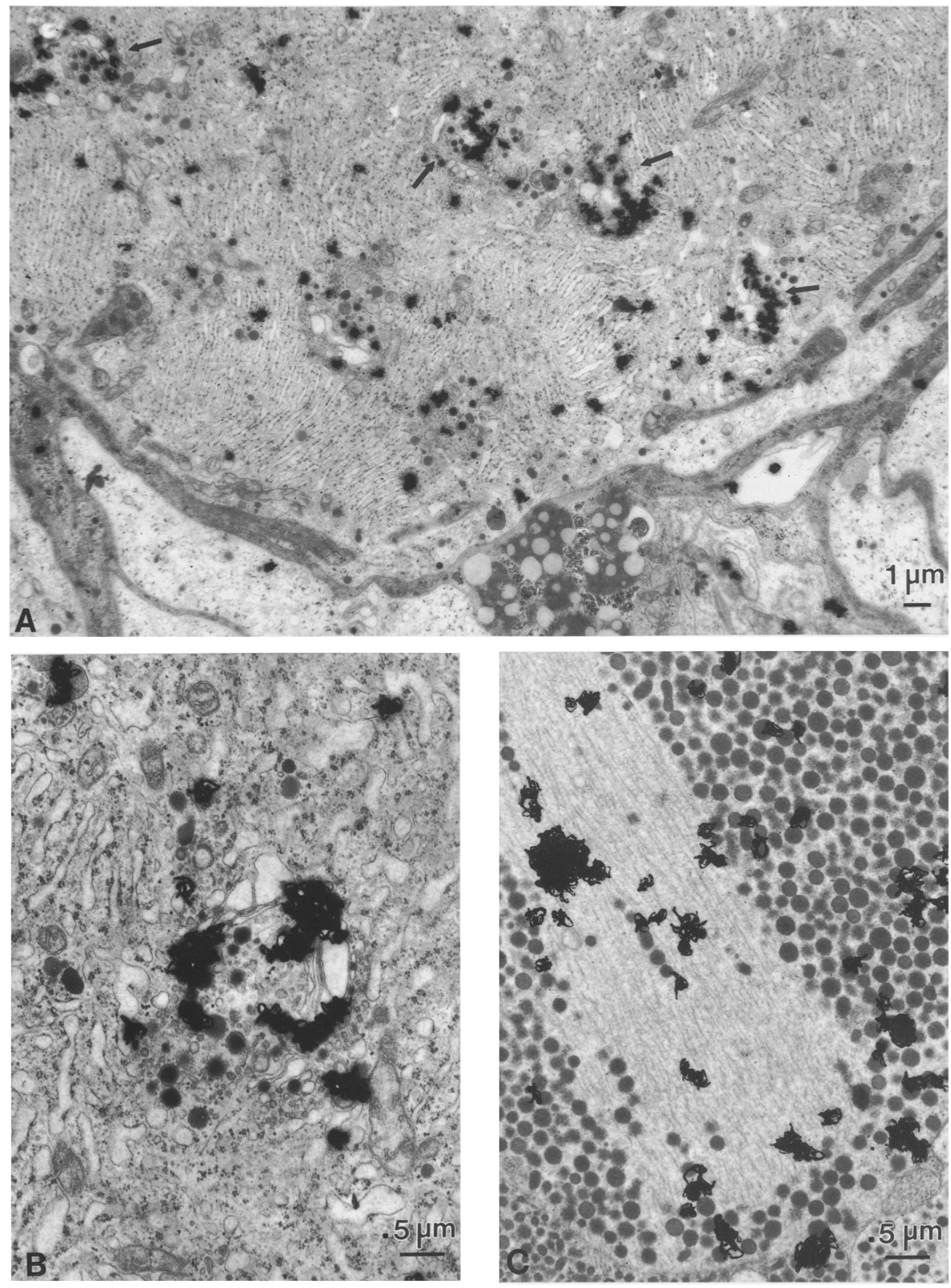
the group of somata, the aggregation of the axonal storage and secretory terminals in a compact neurohemal organ, and especially the separation of somata and terminals by a length (about $1-2 \mathrm{~mm}$ ) of axon tract provide the possibility of well-defined autoradiographic tracking of the newly synthesized peptides because the application of radioactive precursor amino acid can be restricted to the somata. Figure $1 \mathrm{~A}$ shows a photomontage of a longitudinal section through an isolated XOSG system, stained histologically, but not radiolabelled. In Fig. 1B and $\mathrm{C}$, sections through the sinus gland show the clustering of swollen axon-terminal dilatations around a complex of blood (hemolymph) sinuses. Other studies (Nagano 1985, 1986; M. Nagano and I. Cooke, unpublished) have shown that individual axons form a widely branching arborization with complex swellings and narrowings within the sinus gland. In Fig. $1 \mathrm{~B}$ and $\mathrm{C}$ it may be noted that the terminals immediately surrounding sinuses form a smaller size-class than those further from the sinuses. The differences in staining intensity may reflect differences in the nature, state of processing or amount of material stored in the dilatations. In Fig. 1 C, the preparation had received a $5 \mathrm{~h}$ pulse of ${ }^{3} \mathrm{H}$-leucine applied to the somata, followed by a $19 \mathrm{~h}$ chase before fixation. Note that the small-sized processes immediately surrounding blood sinuses are particularly heavily labelled. Figure $1 \mathrm{D}$ shows a section through the cluster of somata from a non-radiolabelled preparation, and Fig. 1E, one from a lightly labelled preparation $(5 \mathrm{~min}$ pulse, $1 \mathrm{~h}$ chase). Both large and small neuronal somata show labelling. In the large somata, the labelling is distinctly clumped within the cytoplasm.

\section{Somatic incorporation of ${ }^{3} \mathrm{H}$-leucine and axonal transport} of radiolabel in granules. EM autoradiography of somata after brief pulse/chase protocols (Fig. 2A, B) shows that the punctate appearance of the label in light micrographs such as Fig. $1 \mathrm{E}$ is the result of the concentration of label at Golgi complexes where it is associated with formed or forming granules. The rapid and highly preferential localization of label at Golgi complexes suggest that the predominant synthetic activity of these neurons is the production of peptide-containing granules.

While we have not given attention to the axon tract, sections that include the transition of axons into terminal dilatations, such as Fig. $2 \mathrm{C}$, show arrays of parallel microtubules with end-to-end rows of granules among and aligned with them. In these transition regions, microtubule arrays are surrounded by densely packed masses of granules. Radiolabel is preferentially found

Fig. 2A-C. Electron-microscopic autoradiographs showing localization of radiolabel in somata and axons. A Cytoplasm of large soma showing labelling of abundant rough endoplasmic reticulum and particularly heavy labelling over formed or forming granules at Golgi complexes (arrows); 5 min pulse/1 h chase (see Fig. $1 \mathrm{E}$ ). B Higher magnification of radiolabelled Golgi complex (as in A). C Section at zone of transition of axons to terminal dilatations. Rows of granules, some radiolabelled, are aligned with central array of microtubules; radiolabel is associated with granules peripheral to the microtubule bundle as well ( $20 \mathrm{~min}$ pulse/ $72 \mathrm{~h}$ chase) over granules that are within or close to microtubule arrays in material fixed after a $19 \mathrm{~h}$ chase.

Time-course of appearance and movement of radiolabel in the terminals. Sections of the neurohemal organ were examined by light-microscopic autoradiography from a series of preparations given a $20 \mathrm{~min}$ pulse of radiolabelled leucine and fixed following various chase times (Fig. 3). Very little radiolabelling was observable in the terminal region at $10 \mathrm{~h}$ (Fig. $3 \mathrm{~A}$ ) or $14 \mathrm{~h}$ (Fig. 3B) after exposure to the label. The section shown in Fig. $3 \mathrm{~B}$ includes a portion of the axon tract near the terminal region in which a dense pulse of radiolabel is evident. In sections of the sinus gland fixed after a $19 \mathrm{~h}$ chase, there was a large increase of radiolabel relative to that seen at earlier times. These observations indicate a rate of axonal transport of $0.1-0.2 \mathrm{~mm} / \mathrm{h}$.

After a $19 \mathrm{~h}$ chase the label was most dense in the band of small terminal profiles that surround blood sinuses. This very clear zonation of the label near blood sinuses was observed in all six of the preparations fixed following a $19 \mathrm{~h}$ chase.

Sections from material that received a $72 \mathrm{~h}$ chase period show label seemingly evenly distributed throughout the terminal dilatations of the sinus gland. The differences in the distribution of the radiolabel in preparations fixed $19 \mathrm{~h}$ as compared with $72 \mathrm{~h}$ after a pulse of ${ }^{3} \mathrm{H}-$ leucine are more easily appreciated in unstained sections, as illustrated in Fig. 4.

Presence of label in terminals of different morphological types. EM autoradiography of sections of the sinus gland establish that the radiolabelling is predominantly associated with granules enclosed in terminal profiles. In Fig. 5 (top), the clustering of label near the blood sinus is again evident. Label is sparse in areas near the sinus lacking granules, possibly representing terminals depleted of granules (Weatherby and Haylett 1985) or processes of glial cells.

Previous EM studies of the sinus gland of this species (Weatherby 1981; Weatherby and Haylett 1985) have described 6 morphologically distinguishable types of terminals. The ${ }^{3} \mathrm{H}$-leucine radiolabel is observable over all of these types (Fig. 5, bottom).

\section{Discussion}

The autoradiographic observations on sections of the crab X-organ - sinus gland system obtained in this study provide clear visual evidence for the rapid (within $1 \mathrm{~h}$ ) selective routing of the labelling leucine in the somata (X-organ) to Golgi complexes, the axonal transport of radiolabel in granules to reach the neurohemal organ (sinus gland) within a day, and its initial direction to and deposition in the granule-filled terminal processes bordering blood sinuses which are sites of secretion. The autoradiographs provide a mechanistic explanation for the preferential secretion of newly synthesized products, as observed in a separate study (Stuenkel 1983; Newcomb et al. 1985) of Cardisoma preparations 

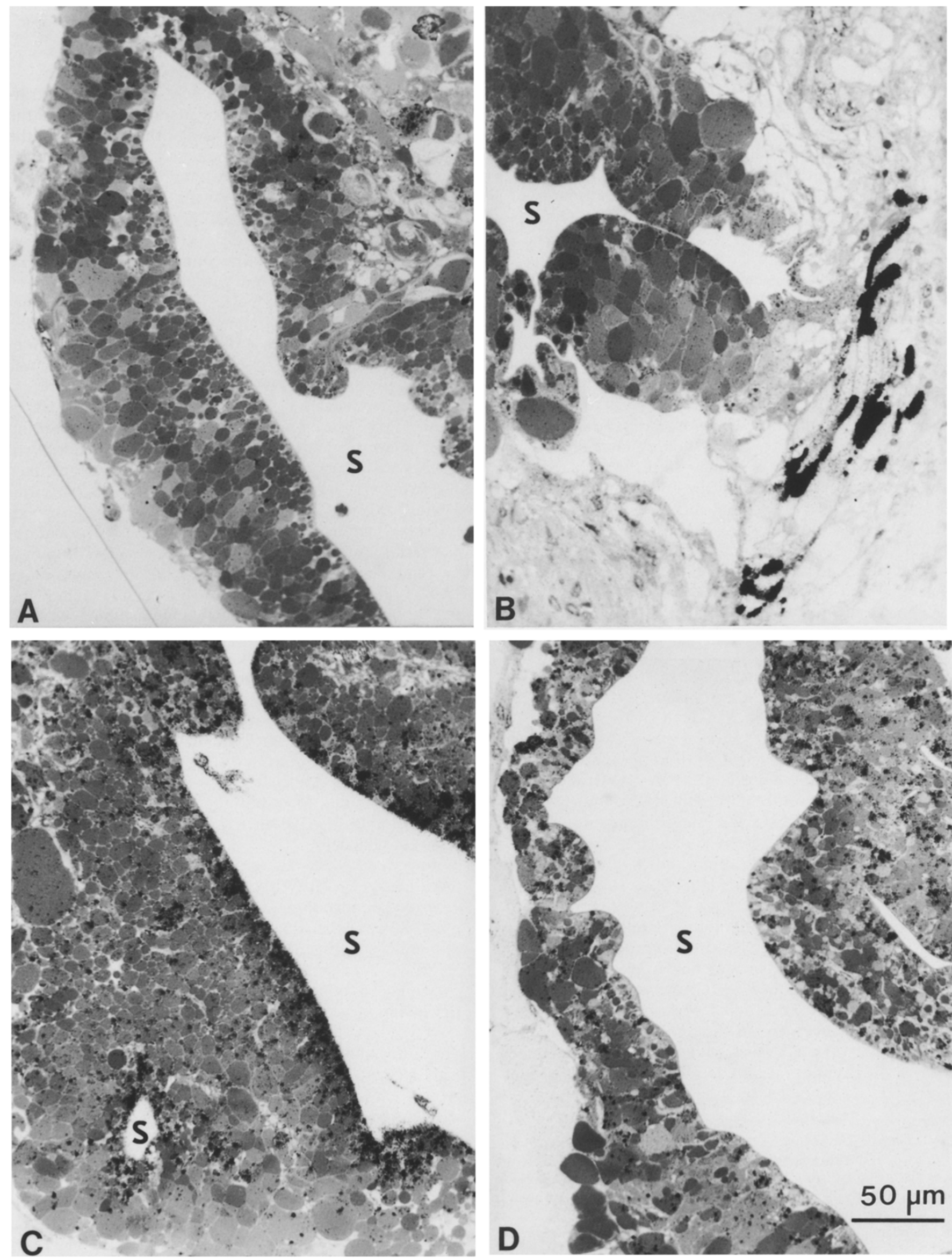

Fig. 3A-D. Light-microscopic autoradiographs showing distribution of transported radiolabelled material in sinus gland with different chase times $(20 \mathrm{~min}$ pulse). A $10 \mathrm{~h}$ chase: almost no exposed grains are present. B $14 \mathrm{~h}$ chase: terminal dilatations with almost no labelling; portion of nerve tract intensely labelled. C $19 \mathrm{~h}$ chase:

label present throughout sinus gland, but concentrated near sinuses (s); see also Figs. 1C, 4 top. D 72 h chase: label uniformly distributed throughout sinus gland; see Fig. 4 bottom. Scale in $\mathbf{D}$ applies to all 

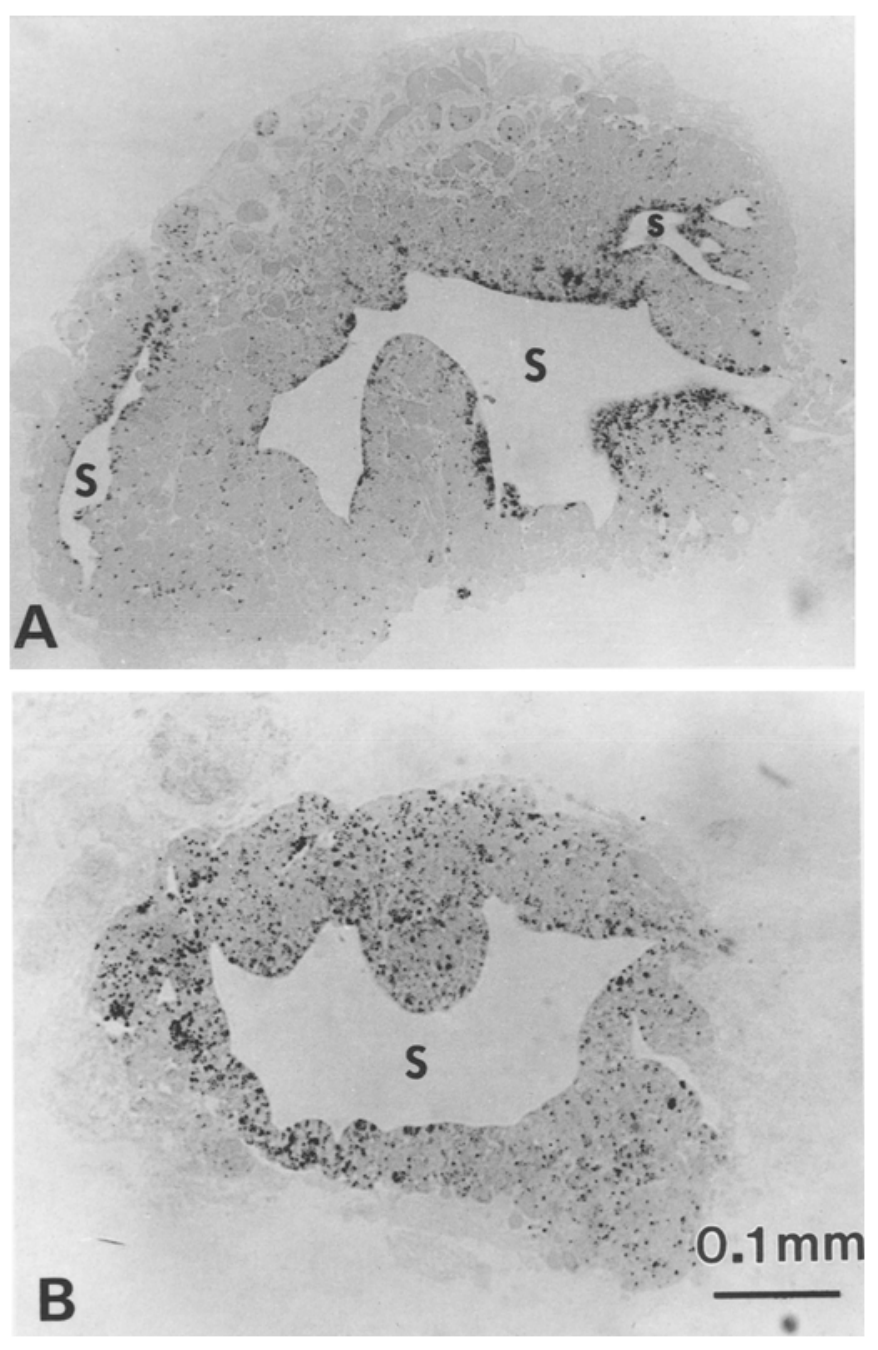

Fig. 4A, B. Light-microscopic autoradiographs of unstained sections of sinus gland. A $20 \mathrm{~min}$ pulse $/ 19 \mathrm{~h}$ chase: exposed grains concentrated near sinuses $(s)$; see Figs. 1 C, 3 C. B 20 min pulse/72 h chase: exposed grains more uniformly distributed over sinus gland; almost absent over surrounding tissue; see Fig. 3D

biosynthetically radiolabelled with a $5 \mathrm{~h}$ pulse $/ 19 \mathrm{~h}$ chase in the same way as those studied here. While the initial delivery of granules appears to be to release sites, after 3 days the radiolabelled material is almost uniformly distributed throughout the granule-filled terminal dilatations of the sinus gland.

The two size-classes of terminal dilatations observed in sections of the sinus gland, with small terminals palisaded against blood sinuses and larger dilatations more distant from the sinuses, suggest their analogy with the endings and swellings of the neurohypophysis (Heap et al. 1975). Serial EM sectioning showed that the small perisinus profiles are finger-like extensions to the blood sinus from the larger, preterminal swellings (Weatherby 1981). In studies of the sinus gland of Cardisoma under normal (Weatherby 1981) or potassium-stimulated conditions (Weatherby and Haylett 1985), as well as in studies of other crustacean species under a variety of conditions (Bunt and Ashby 1968; Shivers 1976; Nordmann and Morris 1980), omega figures suggestive of exocytotic events have been observed only where terminal membrane abuts a hemolymph sinus. Such evidence indicates that areas of contact between terminal membranes and sinuses are the predominant sites of secretion. It is at these sites that radiolabelled material is most concentrated after a $19 \mathrm{~h}$ chase. The paucity of labelling at the same time, in the larger structures through which the labelled granules must pass to reach perisinus sites, argues for their directed transport, perhaps attached to microtubules.

The observations from the crab neurosecretory system are entirely consistent with the earlier observations on the neurohypophysis and the interpretation that the initial delivery of the newly-transported granules to terminals abutting blood capillaries (Heap et al. 1975) accounts for the preferential release of newly-synthesized peptides (Sachs and Haller 1968). The functional categorization of endings as sites of release and swellings as storage depots is in question as a result of more recent work. After tannic acid fixation (Buma et al. 1984), exocytotic profiles were seen associated with swellings and undilated axons, as well as endings (Buma and Nieuwenhuys 1987; Morris et al. 1988), suggesting that release may not be restricted to endings near capillaries. Both in situ (Morris et al. 1988) and in preparations of isolated swellings and endings (Nordmann and Dayanithi 1988), release of vasopressin was correlated with images suggesting that exocytotic events occur at similar frequencies, if calculated in relation to the available membrane area, in swellings and endings. However, the failure to detect non-terminal exocytoses except by means of tannic acid fixation would seem to dictate caution in concluding that non-terminal release contributes significantly to physiological secretory responses. Whether or not release occurs from swellings as well as endings, the smaller volume and larger surface of endings would predict a more rapid turnover of material in them and opportunistic "parking" of granules in available space could account for the autoradiographic observations without requiring that granules remain fixed to a transporter out to the endings (Morris et al. 1988). Biochemical changes with aging of granules (Nordmann and $\mathrm{Ca}-$ zalis 1986) that reduce their probability of release could provide an alternative or additional mechanism for the preferential secretion of the most recently synthesized material. Reconciliation of the new with the earlier observations on the neurohypophysis is incomplete.

Evidence for the directed transport of vesicles to sites of release has been provided in video observations of the movement of fluorescently labelled synaptic vesicles prepared from rat cortex to preterminal active zones following their injection into squid stellate ganglion presynaptic processes (Llinás et al. 1989). However, neither the source of vesicles nor the presynaptic processes represent peptidergic neurons.

Our observations provide some insights on the functioning of peptidergic neurons deserving brief comment. The rapidity and selectivity of the appearance of the labelled amino acid in rough endoplasmic reticulum and Golgi complexes suggest that synthesis of peptides and their packaging for transport in granules is the major biosynthetic operation of these neurons. Our data, while not providing a complete time series, permit estimation of the rate of axonal transport of radiolabel, visually associated with granules, as between $0.1-0.2 \mathrm{~mm} / \mathrm{h}$, 

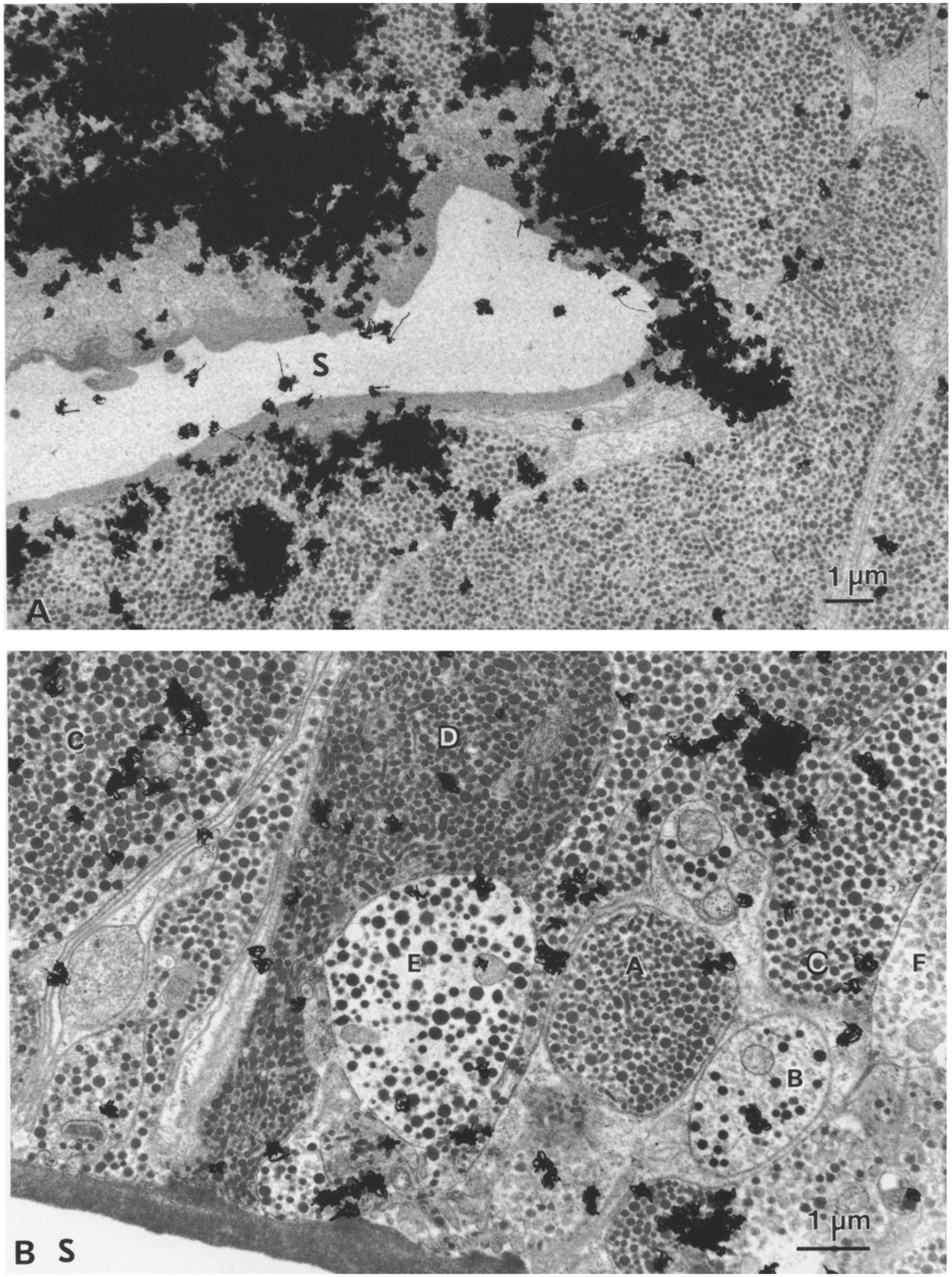

Fig. 5A, B. Electron-microscopic autoradiographs of sinus gland. A Section from preparation receiving a $5 \mathrm{~h}$ pulse $/ 19 \mathrm{~h}$ chase, fixed during stimulation with saline having $10 \times$ normal potassium. Note clustering of exposed grains near sinus $(s)$ and their absence where granules are absent. B Radiolabel over terminals of all six morphological types $(A-F)$ (20 min pulse/19 h chase) 
consistent with transport of granules by microtubuleassociated mechanisms (Smith 1982; Weiss et al. 1987), as is also suggested by images of rows of granules aligned along bundles of microtubules in the preterminal axons. A similar rate of transport was estimated from the radiolabelling observed in sinus glands isolated after pulse/ chase regimes (Stuenkel 1983).

While our observations suggest the directed transport of granules to release sites, they leave unclear the means by which the later redistribution of the radiolabel occurs. We suggest that granules distribute in a diffusional manner to storage areas, with those not participating in exocytotic secretion possibly being displaced by newly arriving granules. Consistent with these suggestions are observations with colchicine (E. Stuenkel and E. Gillary, unpublished), known to disrupt microtubule polymerization. If colchicine was present in the chase, radiolabel failed to reach the sinus gland. If colchicine was added after the first day, when label had reached the sinus gland, it did not alter the uniform distribution of label throughout the neurohemal organ normally observed following a 3 day chase period.

The time scale of a day for material to reach release sites and longer for its general distribution throughout the neurohemal organ can be considered in the light of evidence for the slow, regulated processing of precursor peptides (Newcomb et al. 1985; Newcomb 1987). Differences between animals (but not between right and left sinus glands of the same animal) in the completeness of processing, as indicated by the mixture of peptides in the neurohemal organ, suggest granule-turnover times of weeks. In this respect, the observations are similar to those for the neurohypophysis (Burford and Pickering 1973). Efforts to predict how the mixture of peptides might change with changes in secretory demand, taking into account the processing kinetics and the routes, transport time and geometry of axonal terminations, require computer modeling (Newcomb et al. 1988). Our observations here suggest that, as long as synthesis meets or exceeds the rate of secretory release, the material released will be newly synthesized; the maturational age of the peptide mixture released will be set by the transport time (in this particular preparation under our experimental conditions, between 15 and $19 \mathrm{~h}$ ). In the crab, comparison of the circulating levels of a presumably tonically released sinus-gland hormone, crustacean hyperglycemic hormone (CHH; Keller and Orth 1989) with its rate of synthesis (Stuenkel 1986) suggests that synthesis ensures an excess relative to release, as might also be expected from the presence of large amounts of $\mathrm{CHH}$ in the sinus gland. In the rat, increased secretory demand has been shown to lead within $24-48 \mathrm{~h}$ to increased levels of mRNA in somata synthesizing peptides for release from the neurohypophysis (Sherman et al. 1986). It is not known what signals adjust supply with demand. The crab XOSG system provides a convenient preparation and a relevant model in which to study such questions.

In summary, the observations on the crustacean neurosecretory system are consistent with the long-standing view derived from earlier studies of the neurohypophysis in which terminations abutting the circulatory system are principal sites of release, and the vast majority of newly-formed granules with their contents of newly-synthesized peptides are initially transported there and later, if not released, are displaced to storage areas.

Acknowledgements. We thank R. Newcomb for suggestions on the manuscript and $\mathrm{H}$. Morrow for assistance with electron microscopy facilities. Supported by NSF grants BNS-8404459 and BNS8910432, and NIH grant NS15453 to IC; by a NIH Biomedical Research Support Grant to the University of Hawaii; NIH Research Centers in Minority Institutions grant G12 RR03061; and by the Ida Russell Cades Fund of the University of Hawaii Foundation.

\section{References}

Buma P, Nieuwenhuys R (1987) Ultrastructural demonstration of oxytocin and vasopressin release sites in the neural lobe and median eminence of the rat by tannic acid and immunogold methods. Neurosci Lett 74:151-157

Buma P, Roubos EW, Buijs RM (1984) Ultrastructural demonstration of exocytosis of neural, neuroendocrine and endocrine secretions with an in vitro tannic acid (TARI-) method. Histochemistry $80: 247-256$

Bunt AH, Ashby EA (1968) Ultrastructural changes in the crayfish sinus gland following electrical stimulation. Gen Comp Endocrinol 10:376-382

Burford GD, Pickering BT (1973) Intra-axonal transport and turnover of neurophysins in the rat. Biochem J 136:1047-1052

Chapman DB, Morris JF, Valtin H (1982) How do granules distribute between nerve endings and nerve swellings in the neural lobe? Evidence from Brattleboro rats. In: Baertschi AJ, Dreifuss JJ (eds) Neuroendocrinology of vasopressin, corticotropin and opiomelanocortins. Academic Press, London, pp 1-10

Cooke IM, Sullivan RE (1982) Hormones and neurosecretion. In: Atwood H, Sandeman D (eds) The biology of crustacea, vol 3. Academic Press, New York, pp 206-291

Heap PF, Jones CW, Morris JF, Pickering BT (1975) Movement of neurosecretory product through the anatomical compartments of the neural lobe of the pituitary gland. Cell Tiss Res 156:483-497

Keller R, Orth H-P (1990) Hyperglycemic neuropeptides in crustaceans. In: Epple A, Scanes CG, Stetson MH (eds) Progress in comparative endocrinology. Wiley-Liss, New York, pp 265271

Kent C, Williams MA (1974) The nature of hypothalamo-neurohypophyseal neurosecretion in the rat. A study by light- and electronmicroscope autoradiography. J Cell Biol 60:554-570

Llinás R, Sugimori M, Lin J-W, Leopold PL, Brady ST (1989) ATP-dependent directional movement of rat synaptic vesicles injected into the presynaptic terminal of squid giant synapse. Proc Natl Acad Sci USA 86:5656-5660

Morris J, Pow D, Shaw F (1988) Release of neuropeptides from magnocellular neurones: does anatomical compartmentation have a functional significance? In: Pickering B, Wakerly J, Sumerlee A (eds) Neurosecretion. Plenum Press, New York, pp 113-122

Nagano M (1985) Morphology and intracellularly recorded action potentials of crustacean X-organ - sinus gland systems stained with Lucifer yellow. Proc Jpn Acad 61 B:41-44

Nagano M (1986) Heterogeneity of neurons in the crustacean Xorgan revealed by intracellular recording and injection of horseradish peroxidase. Brain Res 362:379-383

Newcomb R (1987) The amino acid sequence of neuropeptides in the sinus gland of the land crab Cardisoma carnifex: a novel neuropeptide proteolysis site. J Neurochem 49:574-583

Newcomb R, Nordmann JJ (1987) Quantitative HPLC and analysis of rat neurophysin metabolism. Neurochem Int 11:229-240

Newcomb R, Stuenkel EL, Cooke I (1985) Characterization, biosynthesis and release of neuropeptides from the $\mathrm{X}$-organ sinus gland system of the crab, Cardisoma carnifex. Am Zool 25:157171

Newcomb R, Hartline D, Cooke I (1988) Changes in information 
content with physiological history in peptidergic secretory systems. In: Ganten D, Pfaff D (eds) Current topics in neuroendocrinology, vol 9. Springer, Berlin Heidelberg, pp 151-184

Nordmann JJ (1985) Hormone content and movement of neurosecretory granules in the rat neural lobe during and after dehydration. Neuroendocrinology 40:25-32

Nordmann JJ, Cazalis M (1986) Characterization of newly formed and aged granules in the neurohypophysis. J Neurochem 47:1534-1543

Nordmann JJ, Dayanithi G (1988) Release of neuropeptides does not only occur at nerve terminals. Biosci Rept 8:471-483

Nordmann JJ, Morris JF (1980) Depletion of neurosecretory granules and membrane retrieval in the sinus gland of the crab. Cell Tissue Res 205:31-42

Sachs H, Haller E (1968) Further studies on the capacity of the neurohypophysis to release vasopressin. Endocrinology $76: 251-262$

Sherman GT, McKelvy JT, Watson SJ (1986) Vasopressin mRNA regulation in individual hypothalamic nuclei: a northern and in-situ hybridization analysis. J Neurosci 6:1685-1694

Shivers RR (1976) Exocytosis of neurosecretory granules from the crustacean sinus gland in freeze-fracture. J Morphol 150:227252

Smith RS (1982) Axonal transport of optically detectable particulate organelles: In: Weiss DG (ed) Axoplasmic Transport. Springer, Berlin Heidelberg New York, pp 181-192

Sossin WS, Fisher JM, Scheller RH (1989) Cellular and molecular biology of neuropeptide processing and packaging. Neuron $2: 1407-1417$

Stuenkel EL (1983) Biosynthesis and axonal transport of proteins and identified peptide hormones in the $\mathrm{X}$-organ sinus gland neurosecretory system. J Comp Physiol [B] 153:191-205

Stuenkel EL (1985) Simultaneous monitoring of electrical and secretory activity in peptidergic neurosecretory terminals of the crab. J Physiol (Lond) 359:163-187

Stuenkel EL (1986) A common precursor to two major crab neurosecretory polypeptides. Peptides 7:397-406

Stuenkel EL, Cooke IM (1988) Electrophysiological characteristics of peptidergic nerve terminals correlated with secretion. In: Ganten D, Pfaff D (eds) Current topics in neuroendocrinology, vol 9. Springer, Berlin Heidelberg New York, pp 151-183

Weatherby TM (1981) Ultrastructure of the sinus gland of the crab Cardisoma carnifex. Cell Tissue Res 220:293-312

Weatherby TM, Haylett BA (1985) Ultrastructural changes associated with $\mathrm{K}^{+}$-evoked peptide secretion from a neurohemal organ of the crab, Cardisoma carnifex. Cell Tissue Res 242:6773

Weidemann W, Gromoll J, Keller R (1989) Cloning and sequence analysis of cDNA for the precursor of a crustacean hyperglycemic hormone. FEBS Lett 257:31-34

Weiss DG, Seitz-Tutter D, Langford GM, Allen RD (1987) The native microtubule as the engine for bidirectional organelle movements. In: Smith RS, Bisby MA (eds) Axonal transport. Liss, New York, pp 91-111 